www.jmscr.igmpublication.org

Impact Factor (SJIF): 6.379

Index Copernicus Value: 79.54

ISSN (e)-2347-176x ISSN (p) 2455-0450

crossrefDOI: https://dx.doi.org/10.18535/jmscr/v6i10.209

Journal Of Medical Science And Clinical Research

IGM Publication

An Official Publication of IGM Publication

\title{
"OPENER"- Osteoporosis evaluation in north eastern region of India- A prospective demographic study from tertiary hospital of India
}

\author{
Authors
}

\author{
Dr Sharat Agarwal ${ }^{1}$, Dr Manika Agarwal ${ }^{2 *}$, Dr Tobu Pertin ${ }^{3}$ \\ ${ }^{1}$ Associate Professor (Orthopaedics \& Trauma), North Eastern Indira Gandhi Regional Institute of Health \& Medical \\ Sciences (NEIGRIHMS), Shillong (India) \\ Email: drsharat88@yahoo.com, Phone- +91-9436336213 \\ ${ }^{2}$ Associate Professor (Obstetrics \& Gynaecology), North Eastern Indira Gandhi Regional Institute of Health \& \\ Medical Sciences (NEIGRIHMS), Shillong (India) \\ ${ }^{3}$ Senior Resident Doctor (Orthopaedics \& Trauma), North Eastern Indira Gandhi Regional Institute of Health \& \\ Medical Sciences (NEIGRIHMS), Shillong (India) \\ Email: tobupertin@ hotmail.com, Phone- +91-9615620360 \\ *Corresponding Author \\ Dr Manika Agarwal \\ Associate Professor (Obstetrics \& Gynaecology),_North Eastern Indira Gandhi Regional Institute of Health \& Medical \\ Sciences (NEIGRIHMS), Shillong (India) \\ Email:drmanika89@yahoo.com, Phone-+91-9862123245
}

\begin{abstract}
Osteoporosis is one of the most common metabolic bone disease especially so in a developing country like India and can result in devastating physical, psychosocial, and economic consequences. Osteoporosis is characterized by low bone mass with micro architectural deterioration of bone tissue leading to enhanced bone fragility with reduction in both bone quantity and quality. The syndrome includes the triad of back pain, fractures without significant trauma (commonly at spine, hip, distal radius, and proximal humerus) and low mineral density $(B M D)^{1}$.

World Health Organization (WHO) criteria defines a normal T-score value as within 1 standard deviation (SD) of the mean BMD value taken at the lumbar spine and femoral neck in a healthy young adult. For each standard deviation (SD) reduction in BMD, the relative fracture risk is increased 1.5-3 times.

Dual-energy $x$-ray absorptiometry (DXA) is currently the gold standard for the evaluation of BMD.

There are various risk factors associated with the development of osteoporosis. A potentially useful mnemonic for osteoporotic risk factors is 'OSTEOPOROSIS', which indicates: Low calcium intake, Seizure medicine (anticonvulsants), Thin build, Ethanol intake, HypOgonadism, Previous fracture, Thyr Oid excess , Race (white, Asian), Other relatives with osteoporosis, Steroids, Inactivity, Smoking

There is a paucity of literature with regard to the prevalence of this very important health related problem in India, especially north-eastern region of the country.

Therefore, it becomes imperative to know about the magnitude of this preventable problem, its various clinical presentations and the socio-economic profile of the patients suffering from this problem in our setting which has prompted us to undertake such a study here. It will further help us in taking remedial measures to combat this problem in the community. This early diagnosis of osteoporosis would facilitate early initiation of pharmacotherapy and secondary preventive measures using patient education and physical therapy. Keywords: osteoporosis, northeast india, demographic profile.
\end{abstract}




\section{Introduction}

Osteoporosis (OP) is a condition that is represented by a decrease in the bone mass and loss of the micro-architecture of the bone scaffolding that result in increased bone fragility and susceptibility to fractures. ${ }^{(1)}$ It is a physiologic, gender and age-related condition resulting from bone mineral content loss and structural changes in bone. ${ }^{(2,3)}$ A number of factors determine bone strength throughout life including family history, gender, age, menstrual status, dietary habits and the amount of sun exposure and weight-bearing exercise. ${ }^{(4,5,6)}$

Increasing longevity has increased the number of senior citizens globally. It is estimated that currently 200 million people worldwide suffer from osteoporosis. ${ }^{(7)}$ The total burden of osteoporosis accounted for $0.83 \%$ of the global burden of non-communicable diseases, though this varied markedly by region. ${ }^{(8)}$ OP affects both cortical and trabecular bone and the rate of bone loss are approximately two times greater in women than men. According to World Health Organization (WHO) up to $70 \%$ of women over the age 80 years have osteoporosis. ${ }^{(9,10)}$

Approximately $30 \%$ of all postmenopausal women have osteoporosis in the United States and in Europe ${ }^{(11)}$.

An estimated 36 million Indian may suffer from osteoporosis in $2013^{(12)}$. Peak bone mass is usually achieved by the age of 30 years, From the mid-thirties there is a gradual, progressive bone loss, which continues throughout life and is accelerated at the menopause in women. Increasing longevity and a greater proportion of the Indian population over the age of 50 years are likely to result in an increased number of people affected by osteoporosis. ${ }^{(13)}$ Epidemiological hospital based data suggest that men are probably more commonly affected than women, although this may be because the likelihood of men seeking hospital attention is greater than that for the women. ${ }^{(14)}$

India's North-eastern Region consists of eight states - Arunachal Pradesh, Assam, Manipur,
Meghalaya, Mizoram, Nagaland, Sikkim and Tripura - occupying 262,179 square kilometres, which is nearly 8 per cent of the total geographical area of the country and with a population of 39 million (2001 census). ${ }^{(15)}$ The region is located between latitudes 290 and 220 North and longitudes about 89.46 and 97.5/ East. ${ }^{(16)}$ There is totally different socio-cultural, genealogical, geographical, psychological and food habits than with the rest of the country. The geographical location and lack of infrastructural development that has led to deprivation of economic development. ${ }^{(17)}$ Awareness of health problem has created an interest in preventive management of osteoporotic related morbidity and mortality. In north-eastern Region (NER) of India there is very little published literature about clinical epidemiology of osteoporosis; hence there is a great need to make such studies pertaining to the northeast India. This current study intends to find the demographic profile of the patients with Osteoporosis as presented to the tertiary care centre in the north-eastern region of this country.

\section{Materials and Methods}

This study is a cross-sectional hospital based study, conducted on 100 participants (aged with 40 years and above) not having any osteoporotic fracture. The participants were recruited in the out-patient Department of Orthopaedics and trauma and also Gynaecology-Obstetrics, NEIGRIHMS, Shilong, after written consent.

Bone mineral density was evaluated at two sites lumbar spine and the hip, using Dual-energy x-ray Absorptiometry (DEXA). Although various techniques are available for assessing OP, the DEXA technique was used in the present study as it uses a very low level of radiation and is noninvasive. Bone mineral density measured by a DEXA (Dual Energy X ray absorptiometry) is the gold standard in diagnosis of osteoporosis. [18,19] In absolute terms BMD can be expressed as grams of mineral per square centimeter scanned $(\mathrm{g} / \mathrm{cm} 2)$. [20] 
This was a hospital based cross-sectional prospective study, thus the results may not be the true representation of the prevalence in the community.

\section{Inclusion criteria}

Based on National Osteoporosis Foundation (NOF) and International Society for Clinical Densitometry (ISD) recommendations for Bone mineral density (BMD) measurements in the following patients:

- Women aged 65 years or older and men aged 70 years or older, regardless of clinical risk factors

- Younger postmenopausal women and men aged 50-70 years with clinical risk factors for fracture

- Women in postmenopausal transition with a specific risk factor associated with increased risk for fracture (i.e. low body weight, prior low trauma fracture, use of high risk medication)

- Adults with fragility fractures

- Adults who have condition associated with low bone mass or bone loss (e.g, Rheumatoid arthritis)

- Adults who take a medication associated with low bone mass or bone loss (e.g, Glucocorticoids $>5 \mathrm{mg}$ of prednisolone daily for $>3$ months)

- Anyone being considered for pharmacological therapy for osteoporosis

- Anyone being treated for osteoporosis (to monitor treatment effect)

- Anyone not receiving therapy in whom evidence of bone loss would lead to treatment

\section{Exclusion criteria}

It is specially related to the conditions which preclude to performing DEXA scan and are-

- Previous spinal surgery, particularly with metallic implants

- Previous hip surgery, particularly with metallic implants like hip replacement prosthesis, screws, pins etc.

- Those patients who have undergone radiological procedures or investigations within last one week like barium meals or enemas, intravenous pyelograms (IVP) or other nuclear medicine studies

DEXA (Dual Energy X-ray Absorptiometry) studies of hip \& spine were done for all the patients. Patients having $\mathrm{T}$ score of $<2.5$ were considered to be suffering from osteoporosis.

All the participants were evaluated for osteoporosis by DEXA. Demographic profile of patients suffering from osteoporosis was analysed in terms of age, gender, region, dietary habits and educational and employment status.

\section{Results \& Observations Gender}

Out of 100 patients who underwent DEXA scan, 84 were found to be suffering from osteoporosis. In our study, 88 patients were females and out of which 73 were suffering from osteoporosis.

Thus, according to our study, osteoporosis is more common in females than males and since most of the patients were postmenopausal ladies, it is very important to screen all post menopausal women for osteoporosis as $73 / 88$ i.e. $83 \%$ were suffering from osteoporosis.

Though, as per guidelines 12 men were screened, out of which 11 were suffering with osteoporosis, making it as 11 out of 12 men i.e. 91.7\%. Thus, highlighting the importance of screening and treatment of osteoporosis in high risk men.

Table-1 Gender distribution

\begin{tabular}{|l|c|c|c|c|}
\hline S.No & Sex & Normal & Osteoporosis & Total \\
\hline 1. & Female & 15 & $73(83 \%)$ & 88 \\
\hline 2. & Male & 1 & $11(91.7 \%)$ & 12 \\
\hline & Total & 16 & 74 & 100 \\
\hline
\end{tabular}

\section{Religion}

In our study, distribution of patients as per religion is as follows-

Table-2. Religion distribution

\begin{tabular}{|l|c|c|c|c|}
\hline S.No & Religion & Normal & Osteoporosis & Total \\
\hline 1. & Christian & 5 & $15(75 \%)$ & 20 \\
\hline 2. & Hindu & 7 & $55(88 \%)$ & 62 \\
\hline 3 & Jain hindu & 0 & 1 & 1 \\
\hline 4. & Muslims & 3 & $12(80 \%)$ & 15 \\
\hline 5. & Others & 1 & 1 & 2 \\
\hline & Total & 16 & 20 & 100 \\
\hline
\end{tabular}


Thus, irrespective of religion most of the population were osteoporotic.

\section{Region}

All the patients studied were residents of the north eatern region of India as Assam, Meghalaya, Tripura, Nagaland, Mizoram, Sikkim, Manipur and Arunachal Pradesh, thus reflecting that in high risk population, who were screened $84 \%$ were suffering from osteoporosis. It therefore, indicates the need for undertaking community based studies of doing DEXA scan in all patients to understand if osteoporosis is prevalent in low risk patients also. This would help to understand if calcium present in the soil or region and food also is a contributing factor for osteoporosis, if it is also rampant in low risk population in this region.

\section{Dietary habits}

A study of the dietary habits was also made, however the results were inconclusive. Most of the patients were non-vegetarians and osteoporosis was very high in both groups be it vegetarian or non-vegetarian.

Table 3 Dietary habit distribution

\begin{tabular}{|l|c|c|c|c|}
\hline S.No & $\begin{array}{c}\text { Dietary } \\
\text { habit }\end{array}$ & Normal & Osteoporosis & Total \\
\hline 1. & $\begin{array}{c}\text { Non- } \\
\text { vegetarian }\end{array}$ & 15 & $70(82.3 \%)$ & 85 \\
\hline 2. & Vegetarian & 1 & $14(93.3 \%)$ & 15 \\
\hline & Total & 16 & 84 & 100 \\
\hline
\end{tabular}

\section{Education}

Education may be linked with ignorance regarding the importance of nutrition especially role of calcium containing food products in the prevention of osteoporosis. In our study, 45\% people suffering from osteoporosis were less than high school passed although $28 \%$ were educated to the degree level.

Table-4 Education distribution

\begin{tabular}{|l|c|c|c|c|}
\hline S.No & Education & Normal & Osteoporosis & Total \\
\hline 1. & Illiterate & 2 & 13 & 15 \\
\hline 2. & $5^{\text {th }}$ pass & 4 & 22 & 24 \\
\hline 3. & $10^{\text {th }}$ pass & 6 & 20 & 26 \\
\hline 4. & $\begin{array}{c}\text { Post high } \\
\text { school }\end{array}$ & 5 & 28 & 33 \\
\hline & Total & 17 & 83 & 100 \\
\hline
\end{tabular}

\section{Profession}

In this analysis we found that $50 \%$ of the patients who were osteoporotic were unemployed, thus indicating that unemployment may be directly related to poor economic status and associated poor nutrition.

Table-5 Profession distribution

\begin{tabular}{|l|c|c|c|}
\hline S.No & Profession & Normal & Osteoporosis \\
\hline 1. & Aaganwadi worker & 1 & 0 \\
\hline 2. & ASHA worker & 1 & 0 \\
\hline 3. & Clerk & 1 & 3 \\
\hline 4. & Farmer & 1 & 0 \\
\hline 5. & Peon & 0 & 1 \\
\hline 6. & Professional & 1 & 11 \\
\hline 7. & Retired army & 0 & 1 \\
\hline 8. & Semi-professional & 1 & 2 \\
\hline 9. & Semi skilled & 0 & 1 \\
& worker & & 1 \\
\hline 10. & Shop owner & 0 & 2 \\
\hline 11. & Skilled labour & 1 & 1 \\
\hline 12. & Social service & 0 & 0 \\
\hline 13. & Stenographer & 1 & 2 \\
\hline 14. & Teacher & 1 & 5 \\
\hline 15. & Unskilled worker & 0 & 50 \\
\hline 16. & Unemployed & 5 & \\
\hline
\end{tabular}

\section{Discussion}

Awareness about osteoporosis is low in developing countries like India and this condition is still under diagnosed and under treated here. ${ }^{[21]}$ Although the morbidity, mortality and costs of osteoporosis have been well established in postMenopausal women and elderly men, these consequences have not been well studied in an Indian context especially in NE region. However, recent evidence suggests that osteoporosis is an important emerging public health problem ${ }^{[22]}$. This study was aimed at exploring the prevalence of osteoporosis and the risk factors for the same a4mong elderly ambulatory men and women presented to the tertiary care centre in the Northeastern region of the country at NEIGRIHMS, Hospital.

While accurate epidemiological data for Indians is not available, the reports quoted by Gupta ${ }^{[23]}$ show osteoporosis is common at least in those who sustained fractures. Teotia ${ }^{[24]}$ stated that osteoporosis was the commonest metabolic bone disease in post menopausal women which occurred in $35 \%$ of their cases. In our study, 88 
high risk women screened. It was found in 73 patients i.e, $82.9 \%$ cases. This is consistent with the findings of single centre studies on BMD undertaken in Indians (From Bangaluru, Lucknow, Delhi and Chennai) using DEXA scan and have consistently shown lower BMD in Indian Women ${ }^{[25]}$. An article by Sharma et $\mathrm{al}^{[26]}$ emphasizes on the prevalence of osteoporosis and osteopenia in Jammu. In their study, 158 women in the age group of 25-65 years were enrolled and the number of patients suffering from osteoporosis were recorded in the age group of 55-64 years. In our study, only high risk women eligible for screening were enrolled i.e, post menopausal women and $82.9 \%$ of these were osteoporotic. In their study, no woman was found osteoporotic in the age group of 25-34 years, hence there was no need of undertaking screening for osteoporosis in the younger age group of females.

In the study by Sharma et al ${ }^{[26]}, 87.50 \%$ patients of osteoporosis were Hindus. A study by Abraham Samuel Babu etal ${ }^{[25]}$ on osteopenia and osteoporosis in persons attending medical camps in the rural area of north Kerala conducted in the Muslim dominated region between September 2005 and April 2007. Quantitative ultrasound (QUS) of the distal radius using the Omnisense ${ }^{\circledR}$ 7000S was used in these camps for determining the t-scores. The results showed that $53.4 \%$ of the persons were Muslims. In our study, in patients eligible for screening $62 \%$ were Hindus, $20 \%$ were Christians and $80 \%$ were Muslims were suffering from osteoporosis which indicates that irrespective of ethnicity and food habits, osteoporosis is prevalent in all communities.

In our study $82.3 \%$ were non vegetarian patients and $15 \%$ were vegetarian as in North eastern region of this country most of the population is non vegetarian and $82,3 \%$ of non vegetarian and 93.3\% of vegetarian patients were osteoporotic. This indicates the need for calcium and Vit. D supplementation in non vegetarian people also to prevent and treat osteoporosis.

In our study $45 \%$ people suffering from osteoporosis were less than high school in education and $50 \%$ were unemployed, indicating that osteoporosis is prevalent in lower socioeconomic status.

\section{Conclusion}

A major limitation of the study is the relatively limited sample size which impact the power to detect the effect of certain variables deemed relevant by previous literature such as hormone therapy, thyroid hormone, alcohol consumption and smoking. This was a hospital based crosssectional prospective study, thus the results may not be the true representation of the prevalence in the community. However, it does give a bird's eye view of the problem of osteoporosis in the northeastern region of India especially with reference to its association with the demographic profile considering the relationship with the gender, religion, region, dietary habits, education and profession. This study can form a basis to serve as a baseline study on which more cross sectional studies can be undertaken which will go a long way in taking remedial measures to combat this problem in the community and would facilitate early initiation of pharmacotherapy and secondary preventive measures using patient education and physical therapy.

\section{Bibliography}

1. NIH Consensus Development Panel on Osteoporosis Prevention, Diagnosis, and Therapy. Osteoporosis Prevention, Diagnosis, and Therapy. JAMA: The Journal of the American Medical Association. 2001 Feb 14;285(6):785-95. Available from: http://dx.doi.org/10.1001/jama.285.6.785.

2. Juluri R, Prashanth E, Gopalakrishnan D, Kathariya R, Devanoorkar A, Viswanathan $\mathrm{V}$, et al. Association of Postmenopausal Osteoporosis and Periodontal Disease: A Double-Blind Case-Control Study. J Int Oral Health JIOH. 2015 Sep;7(9):119-23.

3. Wactawski-Wende J. Periodontal diseases and osteoporosis: association and 
mechanisms. Ann Periodontol 2001;6(1):197-208.

4. Bassy E.J.osteoporosis \& exercise. Dialogue.2000;32:10-13.

5. Chumelea W.C,Wisemandle W, Guo S.S, and Siervogel R.M. Relation between frame size and body composition and bone mineral status. American journal of clinical nutrition.2002; 75:1012-1016.

6. Flynn A. The role of dietary calcium in bone health. Proceedings of the nutrition society.2003; 62:851-858

7. Epidemiology | International Osteoporosis Foundation [Internet]. [cited 2018 Mar 29]. Available from: https://www.iofbonehealth.org/epidemiolo gy

8. Johnell O, Kanis JA. An estimate of the worldwide prevalence and disability associated with osteoporotic fractures. Osteoporos Int. 2006 Oct 19;17(12):172633.

9. WHO Scientific Group on the Assessment of Osteoporosis at Primary Care Level Summary Meeting Report: Brussels, Belgium, 5-7 May 2004. Geneva, Switzerland: World Health Organization; 2007.

10. $\mathrm{P}$ Chatterjee, $\mathrm{R}$ Kandel, $\mathrm{H}$ Bhatti, $\mathrm{V}$ Challyion, R Chowdhury, G Desai, V Kumar \& A B Dey. Grip strength: An alternative for measuring osteoporosis in elderly. www.tjprc.org. 2014;89-98.

11. Cooper C, Campion G, Melton LJ 3rd. Hip fractures in the elderly: a world-wide projection. Osteoporos Int. 1992 Nov;2(6):285-9

12. Chidambaram P, Anantharaman VV. A Cross-Sectional Study on Bone Density in Adults from an Urban Area of South India.NJRCM: 2018 Jan.-Mar; 7(1): 42-46.

13. Malhotra N, Mithal A. Osteoporosis in Indians. Indian J Med Res 127, March 2008, pp 263-268. 0308.pdf [Internet]. [cited 2018 May 20]. Available from: http://icmr.nic.in/ijmr/2008/march/0308.pd $\mathrm{f}$

14. 2015011reshmaraju.pdf [Internet]. [cited 2018 Apr 17]. Available from: http://repository-

tnmgrmu.ac.in/2147/1/2015011reshmaraju .pdf

15. NORTHEAS.pdf [Internet]. [cited 2018 Apr 29]. Available from: http://web.worldbank.org/archive/website0 1062/WEB/IMAGES/NORTHEAST.PDF

16. Dey R. Recent reforms in elementary education in north-east region states of India through RTE act-Achievement and unfinished tasks. IJAR 2016; 2(6): 887892.

17. Cappellari, L., \& Jenkins, S. P. Summarizing multiple deprivation indicators. ISER(2006). Working Paper 2006-40. Colchester: University of Essex.

18. Brennan RM, Genco RJ, Hovey KM, Trevisan M, Wactawski-Wende J. Clinical attachment loss, systemic bone density, and subgingival calculus in postmenopausal women. J Periodontol 2007;78(11):2104-11.

19. Weyant RJ, Pearlstein ME, Churak AP, Forrest K, Famili P, Cauley JA. The association between osteopenia and periodontal attachment loss in older women. J Periodontol 1999;70(9):982-91.

20. Clinicians guide to prevention and treatment of osteoporosis.National Osteoporosis Foundation. [Internet]. [cited 2015 Jun 29]. Available from: http://nof.org/files/nof/public/content/file/3 44/upload/159.pdf

21. $\mathrm{P}$ Chatterjee, $\mathrm{R}$ Kandel, $\mathrm{H}$ Bhatti, V Challyion, R Chowdhury, G Desai, V Kumar \& A B Dey. Grip strength: An alternative for measuring osteoporosis in elderly. www.tjprc.org. 2014;89-98.

22. Khosla S, Hofbauer LC. Osteoporosis treatment: recent developments and 
ongoing challenges. Lancet Diabetes Endocrinol. 2017 Nov;5(11):898-907.

23. Gupta A. Osteoporosis in India -- the nutritional hypothesis. Natl Med J India 1996;9:268-74.

24. Teotia SPS, Teotia M. Osteoporosis-India: emerging message. $\mathrm{J}$ Assoc Physicians India 1996;44:759-60.

25. Babu AS, Ikbal FM, Noone MS, Joseph AN, Samuel P. Osteoporosis and osteopenia in India: A few more observations. Indian J Med Sci 2009;63:76-7.

26. Sudhaa Sharma, Vishal R Tandon, Annil Mahajan etal. Preliminary screening of osteoporosis and osteopenia in urban women from Jammu using calcaneal QUS. Indian Journal of Medical Sciences 2006; Vol. 60; Issue 5: page 183-189. 